\title{
Seroconversion following Hepatitis B immunization in National Immunization Programme in a selected Medical Officer of Health area in Galle District
}

\author{
Wijayaratne WMDGB ${ }^{1}$, Ubeysekara HA ${ }^{2}$, De Silva $\mathbf{N}^{1}$, Galagoda G $^{3}$ \\ ${ }^{\prime}$ Department of Microbiology, Faculty of Medicine, University of Ruhuna, Galle, Sri Lanka. \\ ${ }^{2}$ Provincial Director of Health Services Office, Southern Province, Sri Lanka. \\ ${ }^{3}$ Medical Research Institute, Colombo, Sri Lanka. \\ Correspondence: Dr.W.M.D. G. B. Wijayaratne \\ e-mail: gayabw@yahoo.co.uk \\ (D) https://orcid.org/0000-0002-8330-3597
}

\begin{abstract}
Introduction: Hepatitis B immunization was introduced into the National Immunization Programme (NIP) of Sri Lanka in three phases in 2003. The study evaluates the protective efficacy of 2, 4, 6 month schedule of hepatitis B vaccination in the NIP in Sri Lanka.

Methods: A cross sectional study carried out among 154 infants (completed 9 months of age) attending the NIP in the Bope Poddala Medical Officer of Health (MOH) area in Galle District in 2008. Hepatitis B surface antibody (HBsAb) titres were tested using a quantitative enzyme immunoassay test. Forty-two infants detected with low titres of antibodies were given a booster dose of hepatitis B vaccine and HBsAb titer was retested 2 - 4 weeks later.

Results: The overall protection (HBsAb titre $>10 \mathrm{mIU} / \mathrm{mL}$ ) after 3 doses of vaccine was $94.2 \%$ with a geometric mean titre of $233.37 \mathrm{mIU} / \mathrm{mL}$. There were $5.8 \%$ infants with $\mathrm{HBsAb}$ titres $<10 \mathrm{mIU} / \mathrm{mL}$ and $30.5 \%$ with HBsAb titres between 10 to $100 \mathrm{mIU} / \mathrm{mL}$. Sex, birth weight, body mass index and weight for height were not significantly associated with HBsAb levels. None of the infants had potential risk factors for acquiring hepatitis B virus infection. Only 26 out of 42 re-vaccinated infants returned for repeat testing of antibody levels where all had demonstrated a protective level.
\end{abstract}

Conclusions: The majority of infants seroconverted following three doses of Hepatitis B vaccine in NIP in Sri Lanka and the rest picked up the antibody levels following a booster dose.

Key words: Hepatitis B vaccine, hepatitis B surface antibodies, seroconversion, infants, Sri Lanka

\section{Introduction}

Hepatitis B virus (HBV) infection is a serious global health problem. In 2015 the global prevalence of HBV infection in the general population was estimated at $3.5 \%$ with about 257 million persons living with chronic HBV infection and 887,220 deaths. The world can be divided into three endemic areas according to the prevalence of Hepatitis B surface antigen (HBsAg) namely high $(\geq 8 \%)$, intermediate $(2 \%-8 \%)$ and low $(<2 \%)$ endemic areas. Prevalence varies considerably among the
WHO Regions, with the highest in the African and Western Pacific Regions (1).

Viral hepatitis is a notifiable disease in Sri Lanka. In the year 2015, the average admission to government hospitals due to viral hepatitis was 12.9 per 100,000 population with the case fatality rate of 0.2 and mainly affecting the age group $25-50$ years (2). The commonest type of viral hepatitis reported in the country was hepatitis A. Sri Lanka has an intermediate prevalence for HBV infection with a prevalence of $\mathrm{HBsAg}$ positivity not more 
than $2.5 \%$ in different selected communities, although it is located in the high endemic region (3). However, a large number of clinically defined hepatitis cases remain unreported as most of them do not seek hospital admission or go to the private sector or visit other allopathic and ayurvedic practitioners.

Safe and effective vaccines against HBV infection have been available since 1982 (4). Routine immunization of infants against hepatitis B was recommended by the World Health organization (WHO) in 1991. This has dramatically decreased the incidence of HBV infection among infants, children and adolescents in many countries (5).

There are two immunization strategies for hepatitis $\mathrm{B}$; routine infant immunization and selective immunization of risk groups. Routine infant immunization is found to be the most cost effective strategy in the prevention of hepatitis B infections even for a country having low endemicity as it prevents HBV infection in all age groups.

Hepatitis B vaccine was introduced into the National Immunization Programme (NIP) of Sri Lanka since 2003 in three phases to all infants at the completion of 2,4 , and 6 months of age (6). Initially a liquid monovalent vaccine used in the NIP which was later replaced the liquid pentavalent vaccine (DTP - HepB+Hib) with the introduction of Hib vaccine into the NIP (5).

The effective level of immunity in a vaccine recipient will be $\geq 10 \mathrm{mIU} / \mathrm{ml}$ which is recommended to test $4-6$ weeks after the last dose of vaccine. Some vaccine recipients with antibody levels $<10 \mathrm{mIU} / \mathrm{ml}$ will develop an adequate level of immunity following an additional booster dose. Primary non-responders, who will not develop protective levels of antibodies even after two courses of vaccines should be informed of their immune status and counselled on how to avoid exposure (7).

The study was conducted to assess the protective efficacy of 2, 4, 6 - month schedule of hepatitis B vaccination in the NIP in a selected population in Sri Lanka. Study determines the percentage of seroconversion following primary vaccination and identifies factors associated with low titres of antibodies following seroconversion. It also evaluates the effect of a booster dose among infants with inadequate level of seroconversion.

\section{Methods}

The study was conducted in the Bope Poddala Medical Officer of Health (MOH) area in Galle District, Sri Lanka from 01/01/2008 to 18/04/2008. It is a semi-urban $\mathrm{MOH}$ area and considered as the field training area attached to the Faculty of Medicine, University of Ruhuna. The field staff members continuously have access to training and are able to update their knowledge, more than in the other $\mathrm{MOH}$ areas. This ensures minimal vaccine failures due to factors like maintenance of cold chain, injection technique and dose / volume of vaccine.

A descriptive cross sectional study was first carried out among infants (having completed 9 months of age) attending the NIP to detect HBsAb titres. The second stage of the study was an interventional study, where infants detected with low titres of $\mathrm{HBsAb}$ in the first stage, were given a booster dose of hepatitis $B$ vaccine and retested for antibodies 2 - 4 weeks later.

The sample size was calculated using formula $\left[\mathrm{n}=\mathrm{Z}_{1-\alpha / 2}^{2} P(1-P) / \mathrm{d}^{2}\right]$ for the descriptive study (8). For this study the proportion $(P)$ of the population estimated to have seroconverted was taken as $90 \%$ by estimating that there will be more than $90 \%$ will be seroconverted following 3 doses of Hepatitis B vaccine given in infancy $(9,10)$. P value of $5 \%$ and absolute precision (d) of 0.05 considered. The final sample size was calculated as 152 with $10 \%$ correction.

All children attending the immunization clinics in the Bope-Poddala MOH area were screened by the principal investigator. Infants who have completed 9 months and who have received all 3 doses of hepatitis B vaccine provided by the NIP and whose parents have consented were enrolled to the study. Exclusion criteria were any infant who has been given a Hepatitis $B$ vaccine not provided by the NIP, immunized for Hepatitis B at any place other than Bope-Poddala $\mathrm{MOH}$ area or having an acute infection at the time of visit.

Data collected using an interviewer administered questionnaire with extraction of certain information from Child Health Development Record and measuring the current weight and length of the infants. Two milliliter of venous blood obtained from the infant by a paediatric nursing officer and tested at the Faculty of Medicine, University of 
Ruhuna, to check the HBsAb titre. All negative samples and those who were having a HBsAb titre of $<100 \mathrm{mIU} / \mathrm{ml}$ were repeated and confirmed.

The HBsAb titre was checked using an EnzymeLinked Immunosorbent Assay (ELISA) test "Monolisa Anti-HBs PLUS" of Bio-Rad, France. The analytical sensitivity was lower than $2 \mathrm{mIU} / \mathrm{ml}$ according to the National Committee for Clinical Laboratory Standards procedure. The specificity is $99.4 \%(98.8 \%-99.8 \%$ with $95 \%$ confidence interval) and the sensitivity is $99.2 \%(98.1 \%-99.7 \%$ with $95 \%$ confidence interval (10).

Optical density (OD) values were recorded on calibrated standards with known HBsAb titres of $10 \mathrm{mIU} / \mathrm{ml}$ (C1), $100 \mathrm{mIU} / \mathrm{ml}(\mathrm{C} 2), 400 \mathrm{mIU} / \mathrm{ml}$ (C3) and $1000 \mathrm{mIU} / \mathrm{ml}(\mathrm{C} 4)$ and a negative control (CO) using different filters at $450 / 620-700 \mathrm{~nm}$ and $405 / 620-700 \mathrm{~nm}$. The assay is validated with following parameters specified by the manufacturer before obtaining test results. The measured OD values of $\mathrm{CO}$ must be $>0.000$ and $\leq 0.070 \mathrm{OD}$ units, $\mathrm{C} 2$ must be $\geq 0.400$ OD units, $\mathrm{C} 1$ must be $\geq 0.050$ and $\leq 0.200$, and each absorbance value of $\mathrm{C} 1$ must be greater than or equal to 1.5 times the OD of the absorbance value of the CO. The mean absorbance of the $\mathrm{C} 1$ is calculated and taken as the cut off value for the assay. The $\mathrm{A} 450$ of $\mathrm{CO}, \mathrm{C} 1$, $\mathrm{C} 2$ and $\mathrm{C} 3$ were graphed versus their assigned concentrations, using a polynomial (quadratic) regression to interpret samples with measured absorbance values less than OD of $\mathrm{C} 3$. A second graph plotted point to point, using A405 of C3 and $\mathrm{C} 4$ calibrators against their assigned concentrations to interpret samples with measured absorbance values greater than OD of C3. Samples with antiHBs titers greater than $1000 \mathrm{mIU} / \mathrm{ml}$ were diluted and re-assayed (11).

The data was analyzed using the Epi Info (TM) 3.4.3 database and statistics software for public health professionals (10/25/2007) from the Centers for Disease Control and Prevention (CDC). Using WHO Anthro V2.0.2 software, WHO growth standards were applied to assess the growth and nutrition of the infants.

Ethical clearance for this study was obtained from the Ethical Review Committee of the Faculty of Medicine, University of Ruhuna and the permission obtained from the Regional Director of Health Services, Galle District to carry out the study.
Medical Officer attached to the Bope-poddala $\mathrm{MOH}$ who is in charge of the immunization clinic were informed of the study.

\section{Results}

The study was carried out in the Bope-Poddala $\mathrm{MOH}$ area in Galle district, Sri Lanka where all the Hepatitis B vaccine doses to the selected infants have been administered from this $\mathrm{MOH}$ area. The vaccine used during this period was a recombinant DNA hepatitis $\mathrm{B}$ vaccine as a multi dose $(10$ dose $)$ vial manufactured in the Serum Institute of India. Batch No. B 2069218. Although the calculated sample size was 152, 154 were included in the study, because all eligible children from the last clinic session who were willing to participate were taken into the study under ethical grounds. The majority had reported no complications following routine vaccination except for fever for 1-2 days recorded in 18\% of vaccinees.

The distribution of HBsAb titre is shown in figure 1 and it is categorized in table 1. The WHO recommended level of protection or the positive cutoff value of $\mathrm{HBsAb}$ titre is $10 \mathrm{mIU} / \mathrm{ml}$. Infants in the study sample who had protective levels of hepatitis B surface antibody titre following primary vaccination were $94.2 \%(145 / 154)$ with a geometric mean titre of HBsAb $233.37 \mathrm{mIU} / \mathrm{ml}$.

\section{Factors associated with an inadequate level of seroconversion following Hepatitis B immunization in infants}

The statistical relationship of probable factors affecting seroconversion with the titre of HBsAb of infants was tested (Table 2). The percentage of non-responders was inadequate to apply statistical tests. Therefore, the non-responders and hyporesponders were taken as one group - "Inadequate" (HBsAb titres $<100 \mathrm{mIU} / \mathrm{ml}$ ) and the rest as "Adequate" (HBsAb titres $\geq 100 \mathrm{mIU} / \mathrm{ml}$ ) for statistical analysis.

The weight (range $-5.0-10.5 \mathrm{~kg}$, mean $=7.95 \mathrm{Kg}$, $\mathrm{SD}=0.98$ ) and the length (range $-62-80 \mathrm{~cm}$, mean $=71 \mathrm{~cm}, \mathrm{SD}=3.12$ ) of infants at the time of the study adhered to the Gaussian distribution. The nutritional status of infants at the time of the study was assessed by the Body Mass Index (BMI), the Gomez classification and the Waterlow 


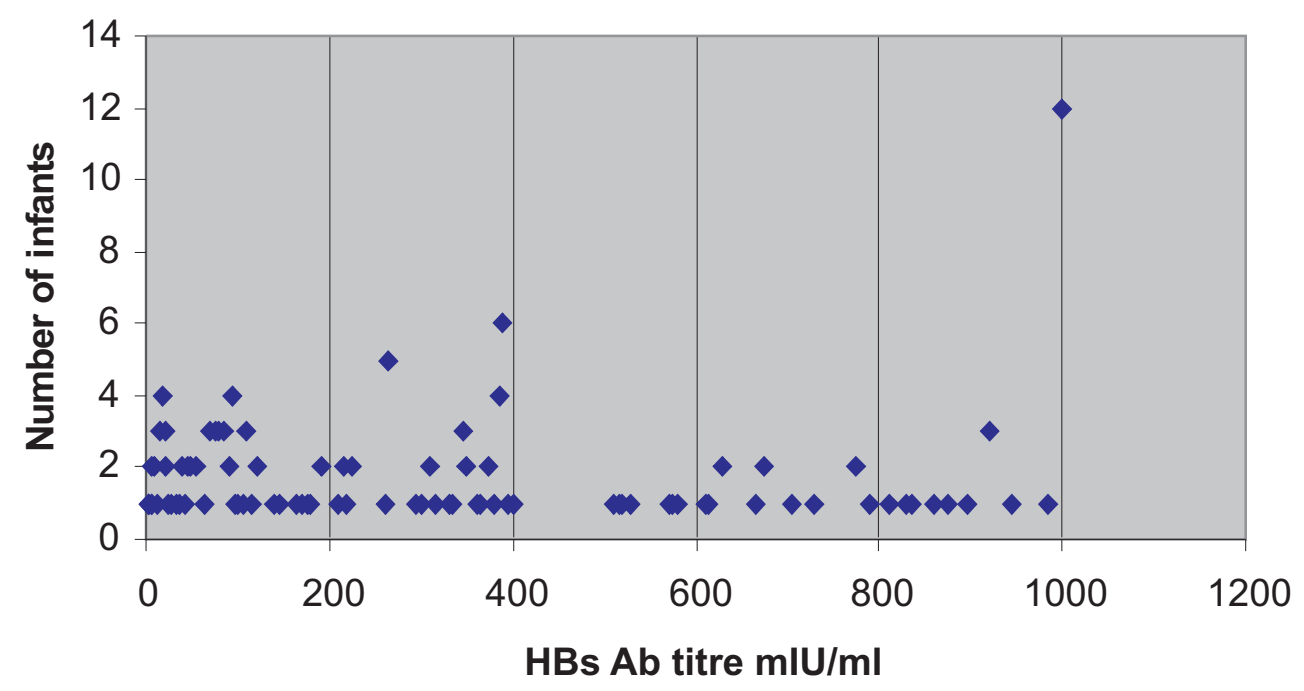

Figure 01: Distribution of HBsAb levels among the sample of infants

Table 1: Category of seroconversion among the sample of infants

\begin{tabular}{lccc}
\hline Category & $\begin{array}{c}\text { Ab titre } \\
(\boldsymbol{m I U} / \boldsymbol{m} \boldsymbol{l})\end{array}$ & Number & Percentage \\
\hline Non-responders & $<10$ & 9 & $5.8 \%$ \\
Hypo-responders & $10-100$ & 47 & $30.5 \%$ \\
Responders & $>100$ & 98 & $63.7 \%$ \\
\hline
\end{tabular}

\section{Risk factors and the level of seroconversion}

None of the mothers were diagnosed to be having hepatitis B or had an icteric illness before pregnancy. Only three mothers were given blood or blood products before delivery and one mother had a complicated pregnancy due to pregnancy induced hypertension. All infants born to these mothers had HBsAb titres of more than $945 \mathrm{mIU} / \mathrm{ml}$. None of the infants were given blood or blood products or became icteric after birth. Only two infants had a stay in Premature Baby Unit having HBsAb titres of $950 \mathrm{mIU} / \mathrm{ml}$ and $20 \mathrm{mIU} / \mathrm{ml}$. Since the numbers were few in each category, statistical testing could not be applied.
The effect of the booster dose of the hepatitis $B$ vaccine among infants having an inadequate level of seroconversion

Fifty-six infants (9 non-responders and 47 hyporesponders) selected from the first stage of the study were offered a booster dose of hepatitis B vaccine. However, only 42 parents of infants ( 9 nonresponders and 33 hypo-responders) voluntarily consented for participation. Of them only 26 infants (3 non-responders and 23 hypo-responders) were brought for repeat testing of HBsAb levels.

Figure 2 shows the change in the distribution of HBsAb levels following the booster dose of hepatitis $B$ vaccine. Among those who came for retesting of HBsAb titer; all the non-responders had HBsAb titre of $>10 \mathrm{mIU} / \mathrm{ml}$ with a geometric mean $\mathrm{HBsAb}$ titre of $699.55 \mathrm{mIU} / \mathrm{ml}$. All hypo-responders had a $\mathrm{HBsAb}$ titres of $>100 \mathrm{mIU} / \mathrm{ml}$ with a geometric mean HBsAb titre of $909.97 \mathrm{mIU} / \mathrm{ml}$. 
Table 2: Relationship of probable factors affecting seroconversion with the titre of HBsAb of infants

\begin{tabular}{|c|c|c|c|c|}
\hline \multirow[t]{2}{*}{ Characteristic } & \multicolumn{2}{|c|}{ Level of seroconversion } & \multirow{2}{*}{$\begin{array}{c}\text { Total } \\
\text { No }(\%)\end{array}$} & \multirow{2}{*}{$\begin{array}{c}p \\
\text { value }\end{array}$} \\
\hline & $\begin{array}{c}\text { Inadequate } \\
<\mathbf{1 0 0} \mathrm{mIU} / \mathrm{ml} \\
\text { No }(\%)\end{array}$ & $\begin{array}{c}\text { Adequate } \\
\geq 100 \mathrm{mIU} / \mathrm{ml} \\
\text { No (\%) }\end{array}$ & & \\
\hline \multicolumn{5}{|l|}{ Gender } \\
\hline Male infants & $29(49.0 \%)$ & $50(51.0 \%)$ & $79(100.0 \%)$ & 0.929 \\
\hline Female infants & $27(51.0 \%)$ & $48(49.0 \%)$ & $75(100.0 \%)$ & \\
\hline \multicolumn{5}{|l|}{ Maturity of infants at birth } \\
\hline Preterm & $9(75.5 \%)$ & $24(24.5 \%)$ & $33(100.0 \%)$ & 0.221 \\
\hline Term & $47(24.5 \%)$ & $74(75.5 \%)$ & $121(100.0 \%)$ & \\
\hline \multicolumn{5}{|l|}{ Birth weight } \\
\hline Normal & $47(38.2 \%)$ & $76(61.8 \%)$ & $123(100.0 \%)$ & 0.342 \\
\hline Low & $9(29.0 \%)$ & $22(71.0 \%)$ & $31(100.0 \%)$ & \\
\hline \multicolumn{5}{|l|}{ Mode of delivery } \\
\hline Vaginal & $42(39.6 \%)$ & $64(60.4 \%)$ & $106(100.0 \%)$ & 0.212 \\
\hline Other (LSCS \& assisted) & $14(29.2 \%)$ & $34(70.8 \%)$ & $48(100.0 \%)$ & \\
\hline \multicolumn{5}{|l|}{ Place of delivery } \\
\hline Government hospital & $53(35.6 \%)$ & $96(64.4 \%)$ & $149(100.0 \%)$ & - \\
\hline Private hospital & $3(60.0 \%)$ & $2(40.0 \%)$ & $5(100.0 \%)$ & \\
\hline \multicolumn{5}{|l|}{ Place of vaccination } \\
\hline $\begin{array}{l}\text { All } 3 \text { doses given at the same } \\
\text { vaccination center in the } \mathrm{MOH} \text { area }\end{array}$ & $48(35.8 \%)$ & $86(64.2 \%)$ & $134(100.0 \%)$ & 0.717 \\
\hline $\begin{array}{l}\text { One or more doses of vaccine given } \\
\text { in a different vaccination centre } \\
\text { within the same } \mathrm{MOH} \text { area }\end{array}$ & $8(40.0 \%)$ & $12(60.0 \%)$ & $20(100.0 \%)$ & \\
\hline \multicolumn{5}{|l|}{ Body mass index (BMI) } \\
\hline$<18.0$ & $45(10.2 \%)$ & $88(89.8 \%)$ & $133(100.0 \%)$ & 0.101 \\
\hline$\geq 18.0$ & $11(89.8 \%)$ & $10(10.2 \%)$ & $21(100.0 \%)$ & \\
\hline \multicolumn{5}{|l|}{ Gomez classification } \\
\hline Normal and Grade 1 malnutrition & $7(94.9 \%)$ & $5 \quad(5.1 \%)$ & $12(100.0 \%)$ & 0.099 \\
\hline Grade 2 and Grade 3 malnutrition & $49 \quad(5.1 \%)$ & $93(94.9 \%)$ & $142(100.0 \%)$ & \\
\hline \multicolumn{5}{|l|}{ Waterlow classification } \\
\hline Normal \& Acute malnutrition & $5(38.5 \%)$ & $8(61.5 \%)$ & $13(100.0 \%)$ & 0.871 \\
\hline $\begin{array}{l}\text { Chronic malnutrition \& Acute on } \\
\text { chronic malnutrition }\end{array}$ & $51(36.2 \%)$ & $90(63.8 \%)$ & $141(100.0 \%)$ & \\
\hline \multicolumn{5}{|l|}{ Mothers employment status } \\
\hline Housewives & $46(33.1 \%)$ & $93(66.9 \%)$ & $139(100.0 \%)$ & 0.010 \\
\hline Employed & $10(66.7 \%)$ & $5(33.3 \%)$ & $15(100.0 \%)$ & \\
\hline \multicolumn{5}{|l|}{ Mothers education level } \\
\hline Less than Grade 10 & $16(45.0 \%)$ & $22(55.0 \%)$ & $40(100.0 \%)$ & 0.187 \\
\hline Equal or greater than Grade 10 & $38(33.3 \%)$ & $76(66.7 \%)$ & $114(100.0 \%)$ & \\
\hline \multicolumn{5}{|l|}{ Number of children in the family } \\
\hline$<4$ & $49(36.0 \%)$ & $87(64.0 \%)$ & $136(100.0 \%)$ & 0.813 \\
\hline$\geq 4$ & $7(38.9 \%)$ & $11(61.1 \%)$ & $18(100.0 \%)$ & \\
\hline
\end{tabular}




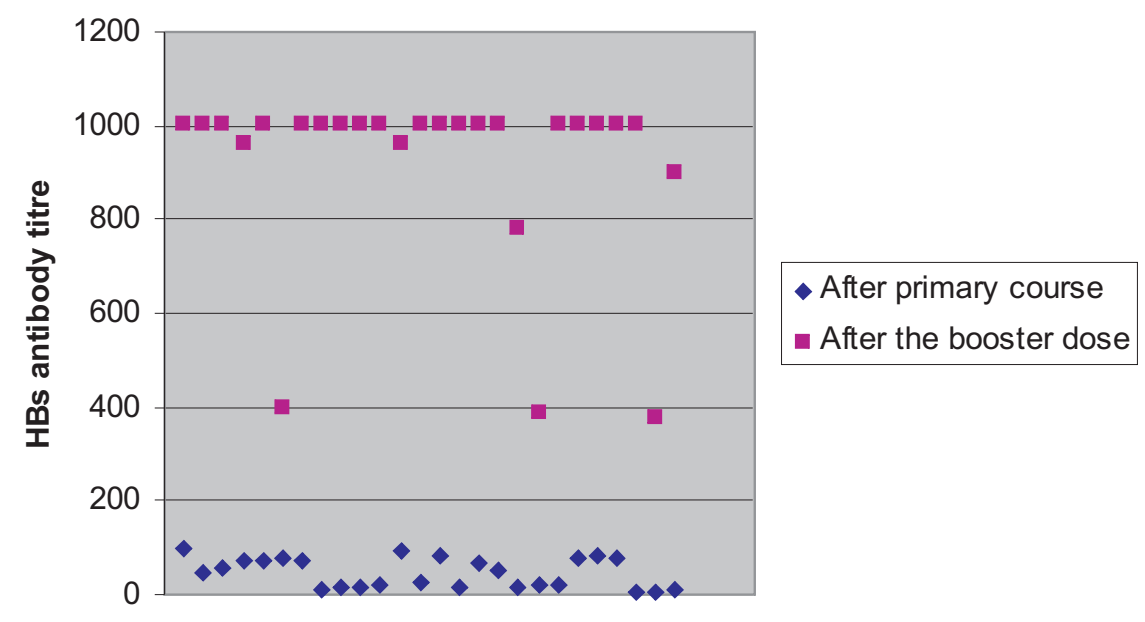

Figure 2: Distribution of HBsAb levels following the booster dose

\section{Discussion}

The study was conducted among a representative sample of infants from a semi-urban community who had all three doses of hepatitis B vaccine (of the same origin and batch) from the same $\mathrm{MOH}$ area.

The WHO recommended level of protection of the positive cutoff value of $\mathrm{HBsAb}$ titre $(10 \mathrm{mIU} / \mathrm{ml})$ was achieved by $94.2 \%$ of infants in the study following the primary vaccination with a geometric mean titre of $233.37 \mathrm{mIU} / \mathrm{ml} \mathrm{HBsAb}$ 's in this group. This seroconversion level among infants in NIP was higher than what was achieved among healthy young adults $(90.3 \%)$ in Sri Lanka (12) and comparable to that among health care workers (95.4\%) in Sri Lanka (13).

Vaccine efficacy studies done among infants of NIP's in India (9) and Taiwan (14) with different vaccination schedules and assessment at different periods after the primary vaccination had seroconversion rates ranging from $77 \%$ to $100 \%$ indicating equivalent results of this study.

Pre-identified probable factors affecting the level of seroconversion include age, sex, birth weight, maturity at birth, nutritional status, and maternal and infant risk factors (10). In this study there was no statistically significant association between sex, birth weight, mode of delivery and maturity at birth with the HBsAb titre following primary vaccination. The number of children in the family, mothers' education level and the nutritional status of the infants assessed by the Body Mass Index (BMI), the Gomez classification and the Waterlow classification were not significantly associated with the HBsAb titre following primary vaccination. There was a statistically significant association between the mothers' employment status and the $\mathrm{HBsAb}$ titre; probably this may have had some impact on nutrition as housewives $(90.3 \%)$ have more time to attend to their children.

The majority of infants or their mothers did not have any identified risk factors for development of HBV infection. Even few infants who had some risk factors had a HBsAb titres of $>10 \mathrm{mIU} / \mathrm{ml}$.

Checking the HBsAb level at the end of a primary course of vaccination is recommended especially for healthcare workers and people at risk to identify non-responders. It is difficult to offer the testing for seroconversion for all infants of the country in a NIP due to the cost and practical problems of getting the consent and drawing blood.

But as in this study, in a NIP a seroconversion level of $>94 \%$ is a higher achievement which eliminates the need of testing for seroconversion. Further, in this study all non-responders and hypo-responders had good serological response depicting 100\% protection against HBV infection following the booster dose of hepatitis B vaccine indicating adequate memory to develop a satisfactory antibody response as protection when exposed to the infection.

Theoretically a booster dose is not indicated in a situation where there are high seroconversion rates 
and a minimal number of primary non responders in a community with a low prevalence of HBV infection and mother to child transmission. But still a routine booster dose to all the infants in the NIP might be beneficial to safely justify that all of them have achieved $100 \%$ seroconversion.

\section{Conclusions and Recommendations}

The majority $(94.2 \%)$ of infants seroconverted following three doses of Hepatitis B vaccine in NIP in Sri Lanka. Therefore, checking the hepatitis B antibody level at the end of the primary course of vaccination, in a routine immunization program of infants is not indicated.

Protective anti-HBs titres were demonstrated by giving a booster dose to infants with inadequate level of seroconversion, depicting a good memory following the primary vaccination and thus a booster dose of vaccine may not be needed in the population of infants vaccinated for hepatitis B in Sri Lanka.

There were no identified factors associated with an inadequate level of seroconversion following Hepatitis B immunization in infants.

Further studies with a larger sample size are needed to detect the overall prevalence of non-responders among infants in Sri Lanka.

\section{Limitations}

The study was limited to one $\mathrm{MOH}$ area to minimize other factors affecting the vaccine efficacy. Thus, the results of this study cannot be generalized. The total study sample size was small and the percentage of non-responders was even smaller and caused difficulties in applying statistical tests, including that for ethnicity.

\section{Funding for equipment and consumables}

Research and Higher Degrees Committee of Faculty of Medicine, University of Ruhuna provided financial assistance for test kits. The additional booster dose of hepatitis B vaccine was arranged with the co-operation of Epidemiological Unit, Sri Lanka and $\mathrm{MOH}$, Bope-Poddala.

Authors declare no conflicts of interests.

\section{References}

1. World Health Organization. Hepatitis B vaccines: WHO position paper - July 2017. Wkly Epidemiol Rec, 2017; 27(92): 369-92.

2. Annual health bulletin 2015. Medical Statistics Unit Ministry of Health, Nutrition and Indigenous Medicine, Sri Lanka; 2017.

3. Noordeen F, Pitchai FNN, Rafeek RA. A review of hepatitis B virus infection in Sri Lanka. Sri Lankan J Infect Dis, 2015; 5(2): 42-50.

4. Lemon SM, Thomas DL. Vaccines to Prevent Viral Hepatitis. N Engl J Med, 1997; 336(3): 196-204. Available from: www.nejm.org/doi/10.1056/NEJM1997011633603.

5. Immunization Handbook. $3^{\text {rd }}$ ed. Epidemiology Unit, Ministry of Health Sri Lanka; 2012.

6. Ministry of Health. Manual of Guidelines on introduction of Hepatitis B Vaccine and AD Syringes to the Expanded Programme on Immunization. Epidemiol Unit, Sri Lanka. 2002;3-6.

7. Jack AD, Hall AJ, Maine N, Mendy M, Whittle HC. What Level of Hepatitis B Antibody Is Protective? J Infect Dis. 1999; 179: 489-92.

8. Lemeshow S, Hosmer DW, Klar J, Lwanga SK. Adequacy of Sample Size in Health Studies. $1^{\text {st }}$ ed. John Wiley \& Sons England; 1991.

9. Kumar, T.S., Abraham, P., Raghuraman, S. \& Cherian T. Immunogenicity of Indigenous Recombinant Hepatitis B Vaccine in Infants Following a 0, 1, 2 - Month Vaccination Schedule. Indian Pediatr. 2000; 37: 7-80.

10. Ribeiro TM, Azevedo RS. Seroconversion of hepatitis B vaccine in infants related to the mother's serostatus in a community of São José Dos Campos, State of São Paulo, Brazil. Clinics. 2006; 61(5): 387-94.

11. Monolisa ${ }^{\mathrm{TM}}$. Anti-HBs PLUS - Ref. 72566 - Enzyme Immunoassay (EIA) for the detection and level determination of antibody to hepatitis B surface antigen (ANTI-HBs) in human serum or plasma. In Bio-Rad, France; 2006.

12. Perera J, Perera B, Gamage S. Seroconversion after hepatitis B vaccination in healthy young adults, and the effect of a booster dose. Ceylon Med J, 2001; 47(1): 6-8.

13. Bandaranayake, V., Gunasena, S., Jayawardena, N. \& Withana N. Anti HBs response following hepatitis B vaccination in a group of health care workers. Bull Sri Lanka Coll Microbiol. 2002

14. Shih, Hsiang-Hung; Chang, Mei-Hwei; Hsu, Hong-Yuan; Lee, Ping-Ing; Ni, Yen-Hsuan; Chen D-S. Long term immune response of universal hepatitis $\mathrm{B}$ vaccination in infancy: a community-based study in Taiwan. Pediatr Infect Dis J, 1999; 18(5): 427-32. 